\title{
Analysis of additional factors for determining heat network pipelines failure rates
}

\author{
Irina Akhmetova ${ }^{1, *}$, and Timur Akhmetov ${ }^{2}$ \\ ${ }^{1}$ Federal State State-subsidized Educational Institution of Higher Professional Education «KSPEU», Kazan, Russia \\ ${ }^{2}$ JSC «Kazenergo», Kazan, Russia
}

\begin{abstract}
The paper suggests the methodology to assess the reliability of both the heat network schemes under design and the existing heat network schemes, that allows to determine availability factor and failurefree operation probability on the basis of the input data including the length, diameter and exploitation time of pipeline segments of the heat networks. As a result of the research, the additional factors that have a significant impact on the reliability of heat supply to consumers have been determined. The impact of these factors on the heat network reliability relying on the experimental data provided by regional heat supply organizations has been assessed. Additional factors were taken into account when developing a new methodology and algorithm for calculating heat supply reliability indices. The program for calculating the consumer heat supply reliability is worked out.
\end{abstract}

\section{Introduction}

The input data for determining the reliability of consumer heat supply systems include failure rates and the average restoration time of heat networks and equipment.

The actual level of reliability in the given heat supply system should be assessed on the basis of the processing of statistical data of the system components failures. Given that statistical samples should meet certain requirements of homogeneity, completeness, and significance [2], the collection of input failure data in each system should be organized in accordance with the form recommended in [3].

If the failure statistics are not used, heat networks failure rate $\lambda$ considering their exploitation time is calculated on the basis of Weibull distribution [4] at an initial failure rate of $1 \mathrm{~km}$ of a single-line heat pipe $\lambda^{\text {in }}$ equal to $5.7 \cdot 10^{-6} 1 /(\mathrm{km} \mathrm{h})$ or $0.051 /(\mathrm{km}$ year) [1]. The initial failure rate corresponds to the period of normal operation of the new heat network pipelines after the early failure period (shake-down period).

The average failure rate of one shut-off control valve is set equal to $2.28 \cdot 10^{-7} 1 / \mathrm{h}$ or $0.0021 /$ year [1].

For heat supply schemes designed for cities and urban districts with a total population exceeding 100 thousand people, reliability indices are calculated referring to the generalized consumers nodes. The thermal accumulation rate of the buildings used in this case is that referring to the buildings representative for this buildings category or for the building presenting the worst heat stability.

To assess the reliability of the heat network schemes under design and the existing heat network schemes,
PJSC «Gazprom Promgaz» has presented a methodology [6], which allows to determine heat network availability factor and failure-free operation probability rate on the basis of the input data including the length, diameter and exploitation time of heat network pipeline segments.

The disadvantage of this approach is that the calculations do not take into account a number of factors directly affecting the heat network reliability.

The purpose of the given research was to identify and take into consideration some additional factors for determining the heat network failures intensity, as well as suggesting a new methodology for calculating consumers heat supply reliability indices.

The goal is achieved by solving the following tasks: - reveal the additional factors that significantly affect the consumers heat supply reliability, but are not considered in the approved methodology and algorithm for heat network reliability calculating;

- assess the additional factors impact on the heat network reliability based on the experimental data provided by regional heat supply organizations;

- consider the additional factors impact in the development of a new methodology and algorithm for calculating consumers heat supply reliability indices;

- present a program for calculating the consumers heat supply reliability indices based on the proposed methodology and calculation algorithm.

\section{Revealing additional factors not considered in the approved methodology}


It was assumed that the following factors affect the heat network segment failure rate, besides their lifespan: the residual pipeline wall metal thickness, the presence of other (preceding) failures in the segment, the soil corrosiveness, the presence of channel flooding (traces of flooding), the heat network pipeline material, the presence of intersections with communications, the percentage of pipeline lot failure.

To solve the issue of considering certain factors in a new methodology and algorithm for calculating the consumers heat supply reliability rates, an analysis of failure statistics in various parts of Kazan city heat network was carried out [7].

Failure statistics were grouped according to the presence of certain factors (a combination of factors). A direct impact on the heat network component failure rates was revealed with regard to the following factors: the residual pipeline wall metal thickness (K1), the presence of other (preceding) failures in the segment (K2), the soil corrosiveness (K3), the presence of channel flooding (traces of flooding) (K4), the presence of intersections with communications (K5).

These factors impact on the consumers heat supply reliability was assessed in [5].

Such factor, as pipeline material, was excluded from consideration because up to date failure statistics have been accumulated referring to the steel pipelines only. The present-day construction materials for designing heat network systems have been coming to stay relatively recently and therefore failure statistics concerning polymer pipelines are not present.

During the data analysis, a direct relationship between the segment exploitation period and the heat network lot failure percentage was revealed (Table 1). Since the network segment lifespan is already taken into consideration as the main parameter of heat network segment failure rate calculation, such additional parameter as the heat network lot failure percentage had to be eliminated.

Table 1. Year of heat network segment commissioning and pipelines lot failure percentage

\begin{tabular}{|c|c|}
\hline Commissioning year & $\begin{array}{c}\text { Pipelines lot failure } \\
\text { percentage (average value), } \\
\%\end{array}$ \\
\hline before 1989 & 85 \\
\hline 1990 & 85 \\
\hline 1994 & 75 \\
\hline 1999 & 75 \\
\hline 2001 & 60 \\
\hline 2002 & 50 \\
\hline 2004 & 50 \\
\hline 2010 & 10 \\
\hline 2012 & 5 \\
\hline
\end{tabular}

\section{Assessment of the additional factors impact on the heat network components failure rates}

According to the methodology [6], the heat network components failure rates are calculated as follows:

$\lambda=\lambda^{\text {init }} \cdot\left(0.1 \tau^{\text {expl }}\right)^{(\alpha-1)}, 1 /(\mathrm{km} \mathrm{h})$

where: $\lambda^{\text {init }}$ - initial failure rate of $1 \mathrm{~km}$ of a single-line heat pipeline; $\mathrm{t}$ expl - network segment exploitation period, years; $\alpha$ - coefficient considering the network segment installation and exploitation features:

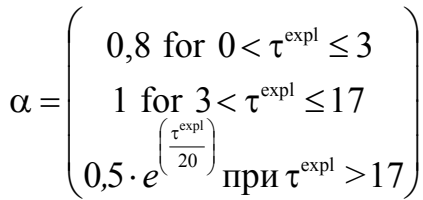

In order to consider the factors revealed in [1], a special coefficient for additional factors was introduced into the existing methodology:

$$
\mathrm{K} i=f(\mathrm{~K} 1 ; \mathrm{K} 2 ; \mathrm{K} 3 ; \mathrm{K} 4 ; \mathrm{K} 5)
$$

Heat network components failure rate, taking into account this coefficient, is calculated according to the formula:

$\lambda=\lambda^{\mathrm{st}} \cdot\left(\tau^{\mathrm{expl}}\right)^{\alpha-1}$

where $\alpha$ - coefficient that takes into consideration the service lifespan of the network segment: $\alpha=0,5 \cdot e^{\mathrm{K}_{i}}=0,5 \cdot e^{f(\mathrm{~K} 1 ; \mathrm{K} 2 ; \mathrm{K} 3 ; \mathrm{K} 4 ; \mathrm{K} 5)}$.

To assess the impact of each coefficient in formula (5), the calculated values of $\mathrm{Ki}$ were determined:

$$
K_{i}=\ln (2 \alpha)
$$

For this purpose, the failure rates for each (i-th) emergency pipeline segment were calculated:

$$
\lambda_{i}=\frac{1}{8760 \cdot \tau_{i}^{\text {эсnл }} \cdot L_{i}},
$$

then, according to the expression obtained by converting formula (4), a special coefficient was determined, considering the heat network segment installation and exploitation features:

$\alpha=\frac{\log \left(\lambda / \lambda_{\text {нач }}\right)}{\log \left(\tau_{\text {экспл }}\right)}+1$

On the basis of the precalculated values of the coefficient $\mathrm{Ki}$, one can assess the impact of additional factors on the heat network components failure rate.

Assessment of any parameter impact was carried out considering failures groups, united by some common factor (a group of factors), as follows:

1. K1 parameter impact.

At the first stage the failures sample analysis was worked out considering a single parameter - the residual pipeline wall metal thickness. The analysis was carried out by comparing the wall thinning with the 
experimental value of the coefficient Ki (Table 2). Wall thinning was calculated according the formula (W.T.):

$$
\text { W.T. }=\left(1-\frac{\text { res.thickness }}{\text { tot.thickness }}\right) \times 100 \%
$$

Table 2. Comparison of wall thinning with the value of $\mathrm{Ki}$

\begin{tabular}{|c|c|c|}
\hline $\begin{array}{c}\text { Wall thinning, } \\
\%\end{array}$ & $\begin{array}{c}\text { Coefficient for } \\
\text { additional factors } \\
\mathrm{K} i\end{array}$ & Present parameter \\
\hline 11,1 & 1,017314159 & $\mathrm{~K} 1$ \\
\hline 12,5 & 1,050576511 & $\mathrm{~K} 1$ \\
\hline 20,0 & 1,081818332 & $\mathrm{~K} 1$ \\
\hline 27,5 & 1,133125107 & $\mathrm{~K} 1$ \\
\hline 34,3 & 1,198338195 & $\mathrm{~K} 1$ \\
\hline 40,0 & 1,233266444 & $\mathrm{~K} 1$ \\
\hline 52,5 & 1,291050063 & $\mathrm{~K} 1$ \\
\hline 54,3 & 1,327608694 & $\mathrm{~K} 1$ \\
\hline 62,5 & 1,372850791 & $\mathrm{~K} 1$ \\
\hline
\end{tabular}

While comparing the parameters, a linear dependence of the additional factors concerning coefficient of $\mathrm{Ki}$ on the residual pipeline metal wall thickness was revealed (Fig. 1):

$$
\mathrm{Ki}=0.00673 \cdot \mathrm{K} 1+0.954
$$

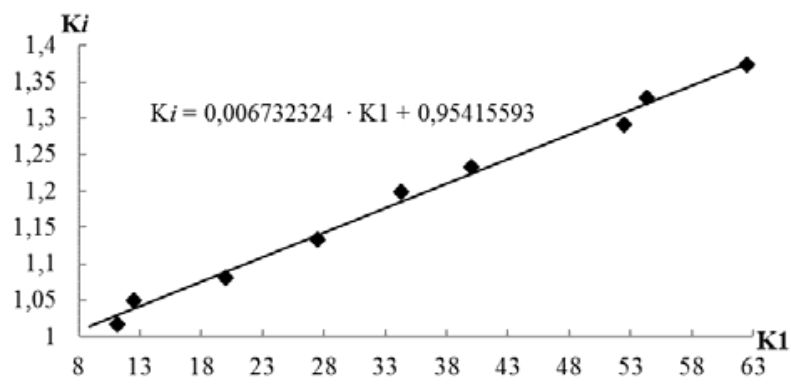

Fig. 1 - The impact of the residual pipeline metal wall thickness on coefficient accounting for additional factors $\mathrm{Ki}$

Since all the remaining cases of heat network component failures include the K1 parameter, the impact of the other factors is determined only by the inclination angle and the shift of this linear correlation line.

\section{2. $\mathrm{K} 1$ and $\mathrm{K} 3$ parameters impact}

At the next stage the failures samples analysis was conducted, which considered two additional factors - the pipeline metal wall thinning and the soil corrosiveness (Table 3).

Table 3. Comparison of wall thinning with the value of $\mathrm{Ki}$

\begin{tabular}{|c|c|c|}
\hline $\begin{array}{c}\text { Wall } \\
\text { thinning, } \%\end{array}$ & Coefficient Ki & $\begin{array}{c}\text { Participating } \\
\text { parameter }\end{array}$ \\
\hline 24,7 & 1,126785915 & $\mathrm{~K} 1, \mathrm{~K} 2, \mathrm{~K} 3$ \\
\hline 25,0 & 1,149985359 & $\mathrm{~K} 1, \mathrm{~K} 3$ \\
\hline 37,5 & 1,187818695 & $\mathrm{~K} 1, \mathrm{~K} 3$ \\
\hline 60,0 & 1,372850791 & $\mathrm{~K} 1, \mathrm{~K} 3$ \\
\hline
\end{tabular}

In the total statistics volume, a single case of pipeline segment failure had occured, which resulted from a combination of three parameters - K1, K2 and K3. It was decided to supplement the sample with this given single case (Figure 2).

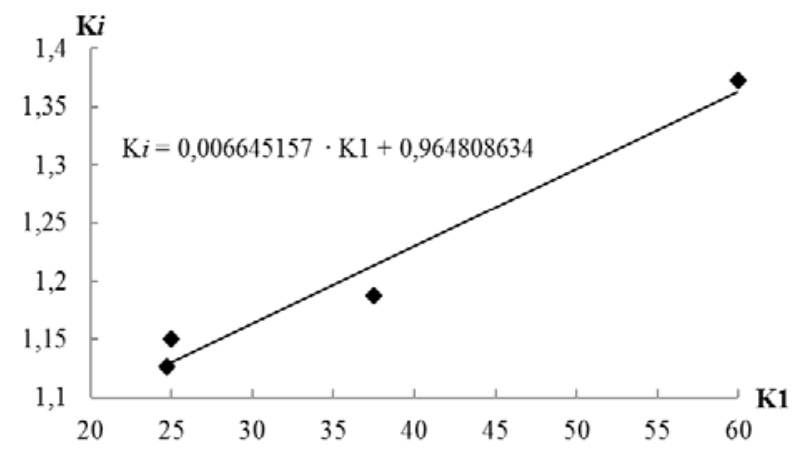

Fig. 2 - K1 and K3 parameters impact on coefficient accounting for additional factors $\mathrm{Ki}$

The functional dependence of the coefficient $\mathrm{Ki}$ on the $\mathrm{K} 1$ and $\mathrm{K} 3$ parameters:

$\mathrm{Ki}=0.00664 \cdot \mathrm{K} 1+0.964$

3. K1 and K4parameters impact.

Further, the analysis of the failure samples was carried out, which includes two additional factors pipeline wall metal thinning and the presence of channel flooding (traces of flooding) (Table 4).

Table 4. Comparison of wall thinning with the value of $\mathrm{Ki}$

\begin{tabular}{|c|c|c|}
\hline $\begin{array}{c}\text { Wall } \\
\text { thinning, } \%\end{array}$ & Coefficient Ki & $\begin{array}{c}\text { Participating } \\
\text { parameter }\end{array}$ \\
\hline 8,9 & 0,952114679 & $\mathrm{~K} 1, \mathrm{~K} 4$ \\
\hline 11,1 & 1,007054898 & $\mathrm{~K} 1, \mathrm{~K} 4$ \\
\hline 13,3 & 1,050576511 & $\mathrm{~K} 1, \mathrm{~K} 4$ \\
\hline 16,5 & 1,039035538 & $\mathrm{~K} 1, \mathrm{~K} 4$ \\
\hline 17,5 & 1,039035538 & $\mathrm{~K} 1, \mathrm{~K} 4$ \\
\hline 22,5 & 1,062634197 & $\mathrm{~K} 1, \mathrm{~K} 4$ \\
\hline 32,5 & 1,102538978 & $\mathrm{~K} 1, \mathrm{~K} 4$ \\
\hline 40,0 & 1,133125107 & $\mathrm{~K} 1, \mathrm{~K} 4$ \\
\hline 42,5 & 1,168133183 & $\mathrm{~K} 1, \mathrm{~K} 4$ \\
\hline
\end{tabular}

The functional dependence of the coefficient $\mathrm{Ki}$ on the parameters K1 and K4 (Figure 3):

$\mathrm{Ki}=0.00494 \cdot \mathrm{K} 1+0.949$ 


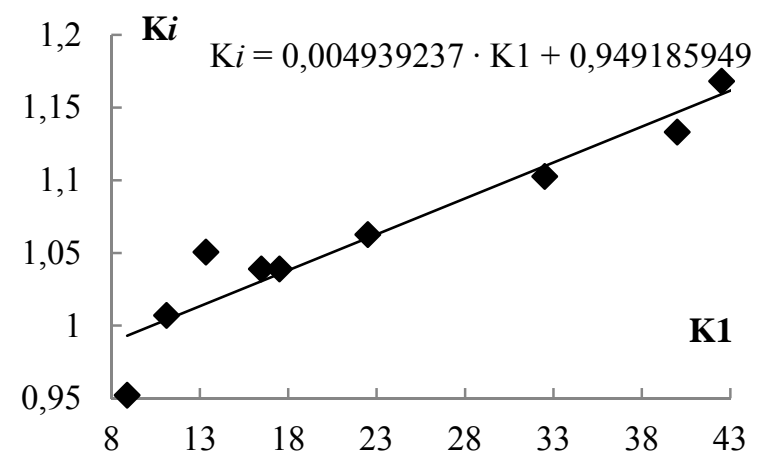

Fig. 3 - K1 and K4 parameters impact on the coefficient accounting for additional factors $\mathrm{Ki}$.

4. $\mathrm{K} 1$ and $\mathrm{K} 5$ parameters impact

The next sample included the following parameters: the pipeline wall metal thinning and the presence of intersections with communications (Table 5).

Table 5. Comparison of wall thinning with the value of $\mathrm{Ki}$

\begin{tabular}{|c|c|c|}
\hline $\begin{array}{c}\text { Wall } \\
\text { thinning, } \%\end{array}$ & Coefficient Ki & $\begin{array}{c}\text { Participating } \\
\text { parameter }\end{array}$ \\
\hline 15,6 & 1,050576511 & $\mathrm{~K} 1, \mathrm{~K} 5$ \\
\hline 30,0 & 1,187818695 & $\mathrm{~K} 1, \mathrm{~K} 5$ \\
\hline 35,0 & 1,220994033 & $\mathrm{~K} 1, \mathrm{~K} 5$ \\
\hline 47,5 & 1,260154364 & $\mathrm{~K} 1, \mathrm{~K} 5$ \\
\hline 62,9 & 1,372850791 & $\mathrm{~K} 1, \mathrm{~K} 5$ \\
\hline
\end{tabular}

The functional dependence of the coefficient $\mathrm{Ki}$ on the parameters $\mathrm{K} 1$ and $\mathrm{K} 5$ (Fig. 4):

$\mathrm{Ki}=0.00641 \cdot \mathrm{K} 1+0.973$

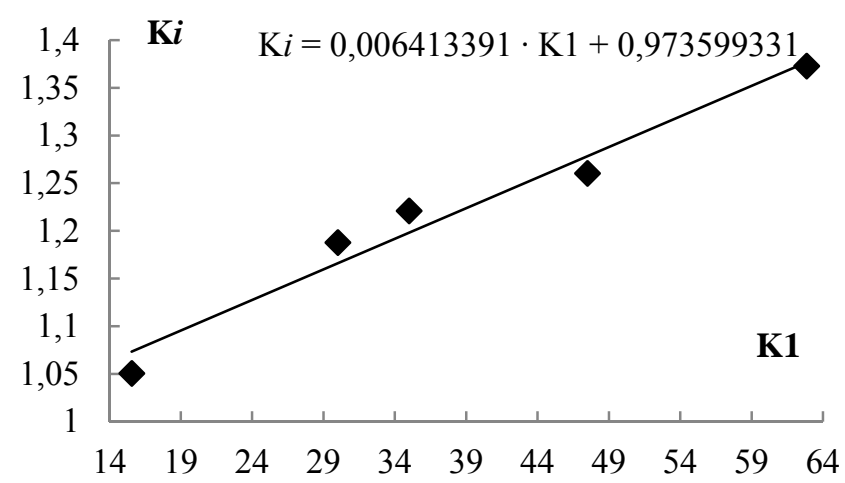

Fig. 4 - K1 and K5 parameters impact on the coefficient accounting for additional factors $\mathrm{Ki}$.

\section{5. $\mathrm{K} 1, \mathrm{~K} 2, \mathrm{~K} 3, \mathrm{~K} 4, \mathrm{~K} 5$ parameters impact}

The final failures sample considered five parameters at once: the thinning of the pipeline wall metal, the presence of other (preceding) failures in the segment, the soil corrosiveness, the presence of channel flooding (traces of flooding and the presence of intersections with communications (Table 6):
Table 6. Comparison of wall thinning with the value of $\mathrm{Ki}$

\begin{tabular}{|c|c|c|}
\hline $\begin{array}{c}\text { Wall } \\
\text { thinning, } \%\end{array}$ & Coefficient Ki & Participating parameter \\
\hline 7,5 & 0,943862731 & $\mathrm{~K} 1, \mathrm{~K} 2, \mathrm{~K} 3, \mathrm{~K} 4, \mathrm{~K} 5$ \\
\hline 11,1 & 1,007054898 & $\mathrm{~K} 1, \mathrm{~K} 2, \mathrm{~K} 3, \mathrm{~K} 4, \mathrm{~K} 5$ \\
\hline 35,0 & 1,134155834 & $\mathrm{~K} 1, \mathrm{~K} 2, \mathrm{~K} 3, \mathrm{~K} 4, \mathrm{~K} 5$ \\
\hline 53,3 & 1,243020534 & $\mathrm{~K} 1, \mathrm{~K} 2, \mathrm{~K} 3, \mathrm{~K} 4, \mathrm{~K} 5$ \\
\hline 62,5 & 1,364564407 & $\mathrm{~K} 1, \mathrm{~K} 2, \mathrm{~K} 3, \mathrm{~K} 4, \mathrm{~K} 5$ \\
\hline
\end{tabular}

The functional dependence of the coefficient $\mathrm{Ki}$ on the parameters K1, K2, K3, K4 and K5 (Figure 5):

$\mathrm{Ki}=0.006889744 \cdot \mathrm{K} 1+0.905045926$

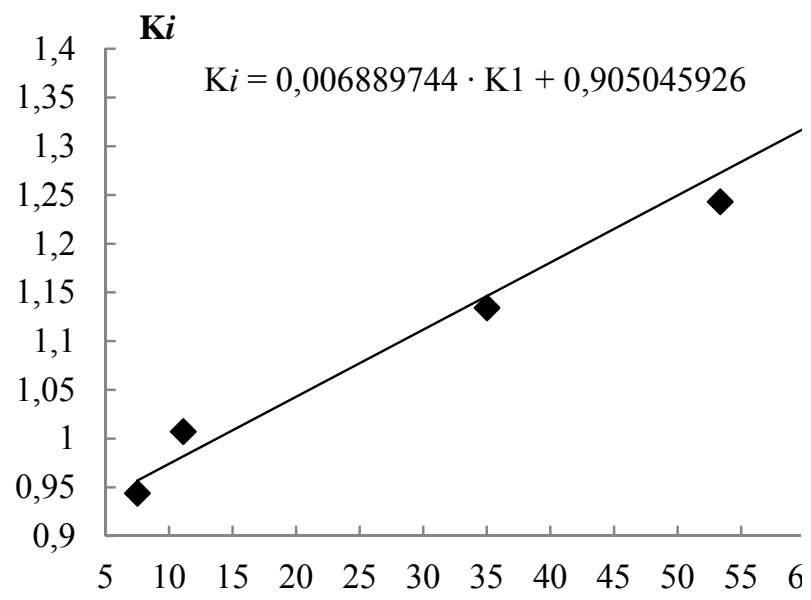

Fig. 5 - the K1, K2, K3, K4 and K5 parameters impact on the coefficient accounting for additional factors $\mathrm{Ki}$

6. Considering the impact of parameters for nonsampled failures.

The remaining single cases of heat network components failure (for example, combinations K1-K2, $\mathrm{K} 1-\mathrm{K} 3-\mathrm{K} 5$, etc.) that were not included in any sample were taken into account by means of the general functional dependence, plotted on the basis of all experimental values of the coefficient Ki (Figure 6):

$\mathrm{Ki}=0.00704 \cdot \mathrm{K} 1+0.918$

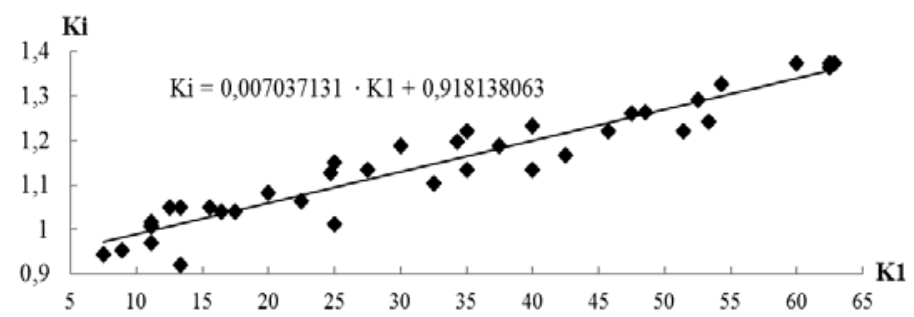

Fig. 6 - General functional dependence for all heat network components failure cases

On the basis of the functional relationships, combined in Table 7, the theoretical values of the coefficient $\mathrm{Ki}$ were calculated. Calculated theoretical 
values of $\mathrm{Ki}$ for all cases of heat network segments failure are given in [5].

Table 7. Functions of additional parameters impact

\begin{tabular}{|l|l|l|}
\hline № & Presence of factors & Functional dependence \\
\hline 1 & $\mathrm{~K} 1$ & $\mathrm{~K} i=0,00673 \cdot \mathrm{K} 1+0,954$ \\
\hline 2 & $\mathrm{~K} 1, \mathrm{~K} 3$ & $\mathrm{~K} i=0,00664 \cdot \mathrm{K} 1+0,964$ \\
\hline 3 & $\mathrm{~K} 1, \mathrm{~K} 4$ & $\mathrm{~K} i=0,00494 \cdot \mathrm{K} 1+0,949$ \\
\hline 4 & $\mathrm{~K} 1, \mathrm{~K} 5$ & $\mathrm{~K} i=0,00641 \cdot \mathrm{K} 1+0,973$ \\
\hline 5 & $\mathrm{~K} 1, \mathrm{~K} 2, \mathrm{~K} 3, \mathrm{~K} 4, \mathrm{~K} 5$ & $\mathrm{~K} i=0,00689 \cdot \mathrm{K} 1+0,905$ \\
\hline 6 & $\begin{array}{l}\text { Combinations of } \\
\text { factors other than } \\
\text { options 1-5 }\end{array}$ & $\mathrm{K} i=0,00704 \cdot \mathrm{K} 1+0,918$ \\
\hline
\end{tabular}

In Fig. 7 the comparison of the theoretical and experimental values of the factor of additional factors $\mathrm{Ki}$ is presented.

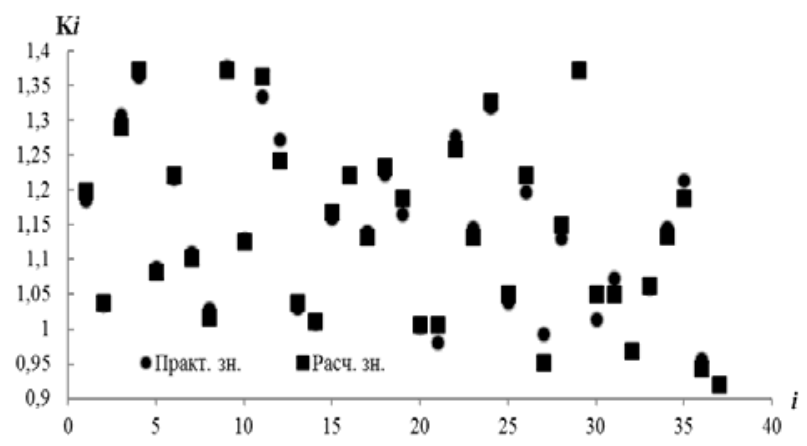

Fig. 7 - Theoretical and experimental values of the coefficient accounting for additional factors $\mathrm{Ki}$.

As can be seen from the graph in Fig. 7, the deviation of the theoretical values from the experimental data is not so significant - the average error does not exceed $1.13 \%$. Thus, the calculations and experimental studies presented in this work have confirmed that the functional dependencies (1) - (15) can be used to calculate the consumers heat supply reliability.

\section{References}

1. Reliability of energy systems and equipment: Reference edition in 4 volumes, edited by acad. Yu.N. Rudenko. V. 4 Reliability of heat supply systems / E.V. Sennova, Novosibirsk: Nauka, 2000 $351 \mathrm{p}$.

2. Barlow R., Proshan F. Statistical Reliability Theory and Testing for Reliability. - Moscow: Nauka. 1984. - $328 \mathrm{p}$.

3. MDK 4-01.2001 "Methodological recommendations for technical investigation and accounting of technological violations in public energy supply systems and the work of energy organizations of the housing and communal services complex" (approved by the Order of the Minister of
Construction of Russian Federation dated 20.08.01 No. 191).

4. Gnedenko V.V., Kovalenko I.N. Introduction to the theory of queuing. - Moscow: Science. - 1987. - 336 p.

5. Akhmetova I.G .System of integrated assessment and centralized heat supply efficiency increase for housing and communal services and industrial enterprises: Thesis for doctor's degree. - Kazan: Kazan State University, 2017. - 32 p.

6. Sennova E.V., Kiryukhin S.N., Shimanskaya A.O. Methodology and algorithm for calculating heat supply reliability indicators for consumers and reserving heat networks for the development of heat supply schemes // Heat supply news. - 2013. - No. 12 (160).

7. Gaidyshev, I.P. Solution of scientific and engineering tasks by means of Excel, VBA and $\mathrm{C} / \mathrm{C}++$. SPb.: BHV-Petersburg, 2004. - $512 \mathrm{p}$.

8. Ivan V. Postnikov, Valery A. Stennikov, Ekaterina E. Mednikova, Andrey V. Penkovskii. A Methodology for Optimization of Component Reliability of Heat Supply Systems // Energy Procedia Volume 105, May 2017, Pages 3083-3088

9. Bożena Babiarz. Reliability analysis in subsystem of heat supply // International Conference on Information and Digital, 2016

10. Z. J. Guo, Z. L. Chen. Case investigation in safety and reliability of a family heat supply system // Materials Science and Engineering Technology. September 2017, pages 905-911 